\title{
Digital Economy: Distributed Project Financing Systems
}

\author{
Belyaev S.E.
}

\author{
Ural Institute of Management - a branch of the Federal State Institution of Higher Education Russian Presidential \\ Academy of National Economy and Public Administration (RANEPA), Yekaterinburg, st. Fevralskoy Revolucii, 15, apt. \\ 123, 620014, Russia \\ Email: Sergey.belyaev2006@gmail.com
}

\begin{abstract}
In modern conditions of the formation and transition to the next technological method of production, the increasingly active use of digital technologies in most industries and sectors of the economy, the study of issues related to digital systems in the field of project financing is becoming increasingly relevant. Distributed project financing systems due to the prevalence and effectiveness of digital technologies makes it possible to raise additional funds including innovative and venture projects, which in recent decades have become the "locomotives" of the development of the economy as a whole. The article presents the theoretical and methodological foundations of the analysis of distributed project financing systems, digital technologies, their use in distributed project financing in the context of the formation and development of the digital economy in Russia and abroad. The analysis of economic and institutional support of the processes of distributed financing of projects, various digital systems in the field of project financing, experience in the formation of the production and technological base of functioning of distributed financing systems for projects based on digital technologies on the example of such countries as the USA, China, Great Britain and Belarus, which allowed us to propose a scheme for the formation of the production and technological base for the functioning of distributed financial systems projects on the basis of digital technologies in Russia, which will make it possible to switch from an import-dependent role in the global software and hardware markets related to distributed project financing systems to the export-oriented positioning of domestic companies and the high capitalization of the IT technology market. It is proposed to use and adapt the Chinese experience in the formation of the production and technological base for the functioning of distributed project financing systems based on digital technologies, taking into account Russian specifics. In addition it was proposed to use the technology of spatial access to the Internet, big data technology and distributed registry technology for the functioning of distributed project financing systems based on digital technologies. Based on the analysis of practical results on the implementation of digital systems in distributed project financing in a number of leading foreign countries, an author's classification of digital systems in the field of project financing was developed with three classification criteria: technological, institutional and economic. Recommendations are formulated on the use of the following sequence of digital technologies in the field of project finance: a national model of the technological basis for distributed project financing - an adapted institutional form of using digital technologies in project finance - an effective type of economic implementation of digital technologies in project finance.
\end{abstract}

Keywords: project finance, digital economy, digital technology, distributed financing

\section{INTRODUCTION}

Digital technologies are becoming more and more widely implemented in all spheres of human life, society and economy. No modern person can imagine everyday life without gadgets, computers, phones. The entire system of interaction and cooperation between people and organizations is now built on the constant, continuous use of digital technologies. The system of economic relations, including on an international scale, is "tied" to the use of digital technologies. Communication, document preparation, settlement and much more are all unthinkable without digital technologies.

No country can stay away from the global trends related to the development of digital technologies. In Russia in 2017 the information society development Strategy for the period 2017 and up to 2030 was adopted and the target program «Digital economy of the Russian Federation» was developed based on the provisions of this strategy [10]. In addition to other goals and objectives this program includes issues related to the development of entrepreneurship in the field of e-Commerce and FINTECH companies. Russia already has a high level of 
Internet availability, digital literacy and a high share of mobile Internet.in addition, experts note a significant pool of specialists in the field of digital technologies. The market of products and services based on the use of digital technologies in Russia currently has national companies that are included in the world rankings of IT companies.

But there are also number of problems in implementing and using digital technologies not only in the national economy as a whole but also in ensuring distributed project financing processes. In the same program «Digital economy of the Russian Federation» is not clear enough or does not specify specific economic objectives in terms of the introduction and use of digital technologies [12]. In Russia, there are very few companies engaged in the development and production of software, electronic component base, the market itself for the turnover of products and services in the field of digital technologies is slightly capitalized compared to the leading countries of the world.

Despite the active use of digital technologies not only in the national economy as a whole but also in the field of ensuring the processes of distributed project financing, there is currently insufficient research on the study and development of theoretical and practical knowledge in the issue of distributed project financing systems, digital technologies, and their use in distributed project financing in the context of the formation and development of the digital economy in Russia.

Digital technologies, their use and the transformation of the system of economic relations in General affect the functioning of the economic mechanism of national economies. The types, nature and quality of digital technologies used in the system of interaction of economic agents change not only the order and methods of settlements and operations for financing economic operations, projects, and investments but also change the essence of social-economic relations, property relations and the nature and quality of property objects.

Financing projects in industries and sectors of the economy is the basis for starting the development and production of goods and services. In a market economy, competition for financial resources is becoming more and more severe. Market participants, institutional sectors and types of activities see the issue of attracting financial resources as a matter of survival and winning the competition. The use and effective use of distributed project financing systems in the context of the formation and development of the digital and electronic economy is becoming increasingly important and the main tool for winning the competition for financial resources and improving competitiveness.

Therefore, the research of these systems within the new architecture of economic relations, the study of the place and role of digital technologies, their use in distributed project financing in the structure of the electronic economy is an extremely relevant direction of socialeconomic and financial analysis at the present time.

3.1 Literature review. Degree of current research problem Research on project financing mechanisms is widely presented in the scientific literature. In particular, such scientists as G. Yeliseyev, V. A. Moskvin, L. N. Ogoleva, Yu. V. Rozhkov, V. S. Stepanova, and E. R. Yeskomb were engaged in this research. $[1,3]$

Further development of the software market, electronic component base, traditional goods and services is impossible without the use of modern methods and technologies for the development of distributed project financing systems, digital technologies and their use in distributed project financing in the context of the formation and development of the digital and electronic economy in Russia.

Such authors as A. A. Nikonov, E. V. Stelmashonok [10] in their research concerning the analysis of the introduction of modern digital technologies in the financial sphere, consider the prospects for the development of one particular industry - FINTECH companies without considering General trends and classifying systems of distributed project financing in the context of the formation and development of the digital, electronic economy.

A review of research in the field of project finance, the formation and development of digital economy, distributed financing systems of Russian scientists such as Babkin A.V., Burkaltseva D. D., Kosten D. G., Vorobyov Yu. N. [9], Obukhova E. A. [11], Savina T. N., Sannikova T. D., Bogomolova A.V., Zhigalova V. N., foreign scientists: Badner V. V. [3], Shaffel P. [7], Paivio A. [8], Yumin Qiu, Hongquan Chen, Zhaohan Sheng, Shuping Cheng [13], Oscar Colombo [6], E. R. Yescomba, Tuska P. [5], Aste T., Pellizona L., Peroni N. [2].

The assessment of the degree of problem development in distributed project financing systems, digital technologies, their use in distributed project financing in the context of the formation and development of the digital and electronic economy in the works of Russian and foreign researchers. If the researchers work focuses on the issues of institutional, legal, and technical support for the formation of the digital, electronic economy and the formation of distributed project finance systems, then foreign experts raise and solve questions about improving and further developing the already formed architecture of distributed project finance systems, digital technologies and the electronic economy.

It is revealed that the Genesis of the development of elements of e-economy and project finance has already been thoroughly reviewed and studied in the works of foreign researchers. In this regard it was decided to analyze the degree of development of the problem abroad and on the basis of this analysis to develop adapted recommendations for the development of distributed project financing systems in Russia.

In the second phase of the study were chosen such countries as USA, China, UK, Belarus. In these countries companies and markets systems for distributed project financing, digital technology, conceptual framework of eeconomy are functioning successfully.

The critical analysis allowed us to identify the advantages and disadvantages of foreign distributed project Finance systems, digital technologies and e-economy elements, develop recommendations and form our own classification 
of distributed project finance systems, digital technologies, e-economy elements, and approaches to their accelerated formation and development.

At the moment such issues as the institutional and economic conditions for the effective implementation and use of digital technologies for distributed project financing and the specifics of the Russian conditions for the introduction and use of digital technologies for distributed project financing have not been sufficiently studied.

\section{RESEARCH METHODOLOGY}

The fundamental questions raised in the research required the use of systemic and institutional approaches, methods of structural-logical analysis and synthesis, and evolutionary analysis.

The system and institutional approaches were chosen because the effect of the use of digital technologies in distributed project financing is manifested in the national economy as a whole due to the system effect of the use of digital technologies in all sectors of the economy, which are best viewed from the perspective of institutions and institutional transformations in the economy.

The method of structural and logical analysis was chosen based on the need to structure and logically link various elements of theoretical provisions and analysis of practical results for the implementation of digital systems in distributed project financing for the purpose of this study. Methods of analysis and synthesis, as General scientific methods, allow us to divide such a complex phenomenon as the essence and role of digital systems in distributed project financing into separate elements, study them separately then generalize the results of the analysis in relation to the process of using digital systems in distributed project financing as a whole single process.

The method of evolutionary analysis allowed us to trace the stages and characteristics of the process of using digital systems in distributed project financing in Russia and abroad.

As part of the study a comparative analysis of the experience of using distributed project financing systems abroad was conducted, which allowed us to identify positive practices and develop recommendations for the implementation of spatial Internet access technologies, big data technologies and distributed registry technologies for the functioning of distributed project financing systems based on digital technologies in Russia as the study of these practices allowed us to identify key priorities in the development of digital technologies in distributed project financing and form an author's position on this issue.

At the first stage of the research we studied the theoretical development of the problem of using digital technologies in distributed project financing in Russia and abroad, which allowed us to identify the most leading and competitive countries in terms of digitalization of the economy in general and in the use of digital technologies in distributed project financing in particular.

The results of this analysis served as the basis for the analysis of practical results on the implementation of digital systems in distributed project financing in the leading countries of the world, which was conducted at the second stage.

The countries were selected based on such criteria as the level of development of digital technologies in the system of economic relations, the level of efficiency of implementation of the strategy for the development of the digital and electronic economy in the country, the volume of distributed project financing using digital systems.

\section{DISCUSSION AND RESULTS}

Experience in the development of distributed project finance systems, digital technologies and their use in distributed project finance in the context of the formation and development of the digital, electronic economy in the United States. The United States of America in 2016 adopted the digital economy Agenda, which notes that the growth and competitiveness of the American economy depend on the effectiveness of the implementation of the strategy for the development of the digital economy in the country. It is no accident that Donald Trump unleashes economic "wars" and initiates proceedings with trade partners, in particular with China, which is already on the heels of the States and in the field of semiconductor production [4]. It is worth noting that the production of electronic products is the third largest export in the United States.

In the USA there has arisen a system of distributed financing of projects due to the high level of development of computer technologies and a large share of the middle class are willing to invest, including in venture capital projects, examples of successful synthesis of these factors are the history of such giants as Apple, Microsoft and several other IT companies occupying today a leading position at international level in the sphere of high technologies. Therefore, it is in the United States that the link has developed: the technological basis for distributed project financing - the institutional system for using distributed project financing systems-improving the efficiency of individual industries and the economy as a whole through the economic implementation of digital technologies in the field of project finance.

Experience in developing distributed project finance systems, digital technologies and their use in distributed project finance in the context of the formation and development of the digital economy in China. Starting with active import and assimilation of advanced technologies in the sphere of digitalization of the economy and production of high-tech products China by 2020, came close to the performance of advanced countries in terms of development costs, digital economy, the production volumes of high-tech products, the share of digital economy in the GDP structure. The dissemination and protection of data on the Internet in China is particularly sensitive, as long as it is the only country that is closest to creating a national Internet network [4]. Digitalization in industry, trade and finance is given priority, work is underway to fill the lack of domestic qualified personnel in 
the field of IT technologies and the disparity in the availability of Internet access in different geographical areas of the country is being eliminated.

China is an example of accelerated adaptation and development taking into account the national specifics of all stages of development of distributed project financing systems, digital technologies and their use in distributed project financing. In the sphere of forming and developing the technological basis for distributed project financing, China is approaching the creation of a domestic Autonomous Internet network protected from the world wide web, which will be as secure as possible in terms of ensuring the processes of distributed project financing. From an institutional point of view, China is developing its own system of institutions that contribute to the accelerated development of the digital economy by actively attracting foreign investment and advanced technologies on preferential terms adapting technologies in national production, patenting assimilated technologies and, on the basis of this, developing its own exports of high-tech products. A clear example of this is the development of $5 \mathrm{G}$ technology, the development of telecommunications and the growth of investment in venture and high-tech projects.

In China the link is as follows: the formation of an Autonomous technological basis for distributed project financing - a flexible institutional system for the use of digital technologies in the field of project finance improving the efficiency of economic implementation of digital technologies in the field of project finance.

Experience in the development of distributed project finance systems, digital technologies and its use in distributed project finance in the context of the formation and development of the digital economy in the UK. As a country with a developed economy, services and high-tech exports, the UK is considered the most "advanced" in Europe in terms of the degree and quality of digitalization of the economy. This is especially evident in e-Commerce and digitalization of the financial sector in the economy. The country has one of the highest levels of Internet distribution and accessibility in the world, as well as the level of digital literacy among the population. The state is actively investing in digital technologies in education and healthcare, construction and other sectors of the real economy.

The problems of development of distributed project financing systems, digital technologies and distributed project financing in the context of the formation and development of the digital and electronic economy in the UK are associated with a greater share of public project financing compared to private investors [5]. There are shortcomings in the strategy for developing technology centers for implementing projects in the e-economy.

A significant achievement and a major area of application of digital technologies, their use in distributed project financing is the financing of projects in infrastructure industries in the development of railways, highways, health and education, the development of which give a systemic effect in the form of large capitalization sector of digital technologies and the economy as a whole that is at the expense of effective system of institutions to use digital technologies in the field of e-economy: the government - private sector - national and private venture capital funds for infrastructure projects based on a welldeveloped technology base of distributed project financing and a high standard of living and income of the middle class as an important institution of distributed project financing.

In the UK the link is as follows: a high level of development of the technological basis for distributed project finance - a well - established effective institutional form of using digital technologies in the field of project finance-a high speed of economic implementation of digital technologies in the field of project finance.

Experience in the development of distributed project financing systems, digital technologies, and their use in distributed project financing in the context of the formation and development of the digital and electronic economy in Belarus. Over the past decade our nearWestern neighbor and partner Belarus has made a significant breakthrough in the development of distributed project financing systems, digital technologies and their use in distributed project financing in the context of the formation and development of the digital economy. The creation of a high-tech park, the formation of a favorable ecosystem for the development of advanced technologies in distributed project financing through the use of blockchain technologies, crowdfunding, crowdinvesting and crypto tools allowed the country to become a confident player in the global software market attracting investment not only within the country but also from abroad.

The main factor that can delay or hinder the development of distributed project financing systems, digital technologies, and their use in distributed project financing in the context of the formation and development of the digital and electronic economy in Belarus may be the human factor [4]. Entrepreneurs-innovators are aimed at the global market, the population does not yet have a sufficient level of digital literacy for a wider use of digital technologies and their use in distributed project financing, so the hi-tech Park remains an "oasis" for the development of the electronic economy in Belarus.

An important achievement in the development of digital technologies and their use in distributed project financing in Belarus should be considered the formation of such an institution for the development of digital systems in the field of project finance as the creation of a class of entrepreneurs-innovators in the context of special economic clusters and a favorable ecosystem for the development of advanced technologies in distributed project financing through tax incentives and state support. Therefore the bundle is the following in Belarus: development of custom modifications to the technological basis for distributed project financing - adapted institutional form use of digital technologies in the field of project financing - large role of the state in improving economic efficiency of implementation of digital technologies in the field of project financing. 
- Internet of things;

In the classifications of a number of authors such as Babkin A.V., Burkaltseva D. D., Kosten D. G., Vorobyov Yu. N. [9] there are three groups of digital technologies: instrumental, infrastructure and applied digital platforms. The classification is based on the allocation of the technological component of project financing without taking into account the institutional and economic aspects of the development of digital systems in the field of project finance.

Such foreign authors as Yuming Qiu, Hongquan Chen, Zhaohan Sheng, and Shuping Cheng [13] have focused on the institutional component of implementing digital technologies in the field of project finance dividing the set of digital technologies in the field of project Finance into international, national and group institutions of project finance without taking into account the technological component.

We propose to eliminate the shortcomings of the above classifications and make a systematic classification of digital systems in the field of project finance.

The author's classification of digital systems in the field of project finance will have three classification criteria: technological, institutional and economic.

Technological digital technologies in the field of project finance:

- broadband Internet for distributed project finance systems;

- $\quad$ mobile Internet for the operation of distributed project finance systems;

- wireless Internet for the operation of distributed project finance systems;

These technologies are the General basis for the application of digital systems in the field of project finance.

Institutional digital technologies in the field of project finance:
- artificial intelligence;

- wireless communication technology;

- digital technologies for collecting big data for the functioning of distributed project finance systems;

- digital big data processing technologies for distributed project finance systems;

- digital big data storage technologies for the operation of distributed project finance systems.

Economic digital technologies in the field of project finance:

○ crowdfunding technologies;

○ technology knowdledge;

- crowdinvesting technologies;

○ blockchain technologies and others.

Economic digital technologies in the field of project finance allow implementing technologies of the previous two groups of technologies in the actual financial flows within specific projects in various industries and sectors of the economy.

Hence, in this structure we use the proposed sequence of implementation of digital technologies in the field of project finance: the model of the technological basis for distributed project financing - the institutional form of using digital technologies in the field of project finance the type of economic implementation of digital technologies in the field of project finance.

In the case of China the sequence of implementation of digital technologies in the field of project finance will be as follows (see figure 1).

For Russia we propose the following sequence and composition of stages of implementation of digital technologies in the field of project Finance (see Fig. 2).

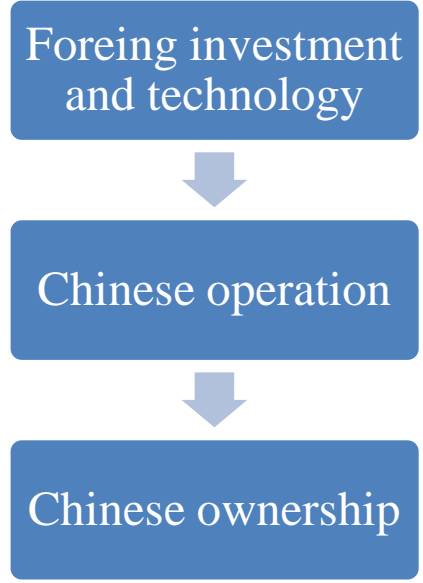

Figure 1 Sequence and composition of stages of implementation of digital technologies in the field of project Finance in China 


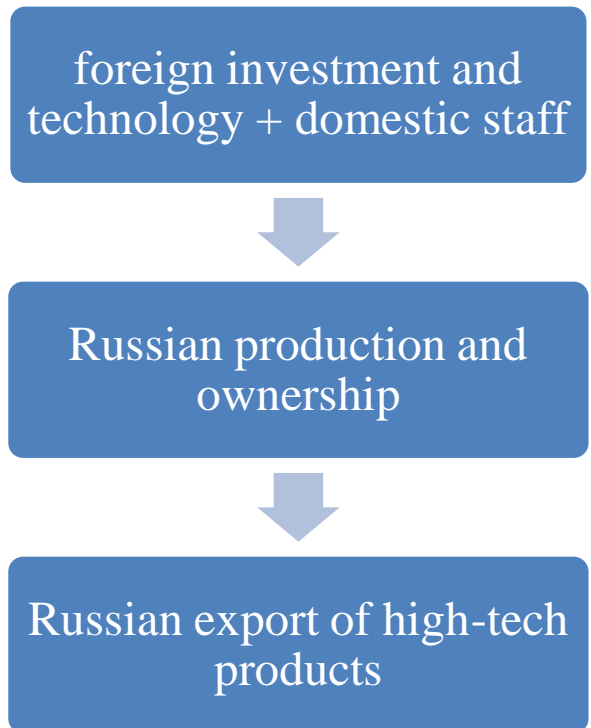

Figure 2 Sequence and composition of stages of implementation of digital technologies in the field of project Finance in Russia

The Russian scheme for implementing digital technologies in the field of project finance useing the advantages of Russia in the field of digital technologies, consisting in the availability of a qualified workforce (programmers, electronics engineers, mathematicians) and a partial production base for the accelerated development of distributed project financing systems based on digital technologies.

In terms of the technological basis for distributed project financing, it is necessary to create its own software and electronic element base in the field of digital technologies - this can be the creation of its own end-to-end technology or the development of an existing one.

The institutional component of implementing digital technologies in project finance is extremely underdeveloped in Russia in comparison with the leading countries in this area, both in terms of legislation and in terms of the presence of an active middle class, institutions of trust in the use of digital technologies in project finance from both enterprises and credit and financial institutions.

The presence of problems in the technological and institutional components of the implementation of digital technologies in the field of project finance makes it difficult to implement the economic stage of the implementation of digital technologies in the field of project Finance.

Recommendations based on the current situation in the field of IT technologies in Russia. Currently in Russia, it is possible to use spatial Internet access technologies, big data technologies and distributed registry technologies for the operation of distributed project financing systems based on digital technologies.

In economic and institutional terms, the development of distributed project Finance systems based on digital technologies requires:
- systematic, transparent legislation in the sphere of intellectual property turnover, software production and electronic element base;

- large amounts of funding for education and science to train qualified specialists (programmers, electronics engineers, mathematicians);

- development of the software market infrastructure and electronic element base.

\section{CONCLUSION}

The analysis and recommendations on the development of distributed project finance systems in Russia will speed up the process of formation and development of distributed project finance systems, digital technologies, elements of the electronic economy, move from an import-dependent role in the world markets of software and hardware associated with distributed project finance systems to export-oriented positioning of domestic companies and high capitalization of the IT market.

Classification of digital systems in the field of project finance will contribute to the institutional development of the intellectual property market, software production and electronic element base.

In this study in comparison with the research of domestic scientists, there is a similarity in the objective need to develop distributed project financing systems, digital technologies and elements of the electronic economy. The differences are in the recognition of the priority of institutional factors in the formation of distributed project 
[5] Handbook of Digital Currency. Bitcoin, Innovation, Financial Instruments and Big Data. Ed. by David Lee Kuo Chuen. L.: Elsevier, Academic Press, 2015.

[6] Oskar, ColomboThe Use of Signals in New-Venture Financing: A Review and Research Agenda. - First Published March 24, 2020. - Research Article: https://doi.org/10.1177/0149206320911090

[7] Schueffel P. Taming the Beast: A Scientific Definition of Fintech / / Journal of Innovation Management. 2017. Vol. 4, No. 4. P. 45.

[8] Paivio, A. imagination and verbal processes, Psychology Press, 2013.

[9] Babkin A.V., Burkaltseva D. D., Kosten D. G., Vorobyov Yu. N. Formation of the digital economy in Russia: the nature, characteristics, technical normalization, the problems of development // Scientific and technical Bulletin of Spbpu. Economic Sciences. - 2017. - Vol. 10. - No. 3. - P. 9-25. GOD: $10.18721 / \mathrm{J} 10301$

[10] Nikonov A. A., Stelmashonok E. V. Analysis of implementation of modern digital technologies in the financial sphere // Scientific and technical Bulletin of Spbpu. Economic Sciences. - 2018. - Vol. 11. - No. 4. P. 111-119. DOI: 10.18721/JE. 11408

[11] Obukhova E. A. ICO as a modern way of financing high-tech projects / / ECO. - 2018. - № 3. - P. 181-192.

[12] Savina T. N. Digital economy as a new paradigm of development: challenges, opportunities and prospects / / Finance and credit. 2018. Vol. 24. - No. 3. Pp. 579590.

[13] Yuming Qiu, Hongquan Chen, Zhaohan Sheng, Shuping Cheng Managing institutional complexity in megaproject organizations / / International Journal of Project Management. - Volume 37, Issue 3, April 2019, Pp. 425-443. https://doi.org/10.1016/j.ijproman.2019.02.001 Banking Services in the Twenty-First Century. Tasca P., Aste T., Pelizzon L., Perony N. (Eds.). N. Y.: Springer, 2016.

[3] Budner, W. W. Cluster Economics and industrial policy: theory and tools / Budner W. W., Palicki S., Pawlicka K.: monograph of Saint Petersburg: Polytechnic University Publishing house, 2015. - 523 p.

[4] Carol Co. Fintech does not disrupt banks, they just fill in gaps // Computerworld Hong Kong Fourth. 2016. 